\title{
Correction to: A review on fisheries and conservation status of Asian horseshoe crabs
}

\author{
B. Akbar John ${ }^{1}$ - B. R. Nelson ${ }^{2} \cdot$ Hassan I. Sheikh ${ }^{1}$. S. G. Cheung ${ }^{3} \cdot$ Yusli Wardiatno $^{4,8}$. \\ Bisnu Prasad Dash ${ }^{5} \cdot$ Keiji Tsuchiya $^{6} \cdot$ Yumiko Iwasaki $^{7} \cdot$ Siddhartha Pati $^{5}$
}

Published online: 20 October 2018

(c) Springer Nature B.V. 2018

\section{Correction to: Biodiversity and Conservation https://doi.org/10.1007/s10531-018-1633-8}

In the published article, in the Abstract (line 3) and the Introduction (line 13), the scientific name of Tachypleus gigas was incorrectly given as Tapinauchenius gigas. The correct generic name is Tachypleus, a genus of xiphosuran arthropods, whereas Tapinauchenius is a genus of an arachnid. We apologise for any confusion this error may have caused.

The original article can be found online at https://doi.org/10.1007/s10531-018-1633-8.

B. Akbar John akbarjohn50@gmail.com

$\triangle$ B. R. Nelson brav_11@hotmail.com

1 Institute of Oceanography and Maritime Studies (INOCEM), Kulliyyah of Science, International Islamic University Malaysia, 25200 Kuantan, Pahang, Malaysia

2 Tropical Biodiversity and Sustainable Development Institute, Universiti Malaysia Terengganu, 20130 Kuala Nerus, Terengganu, Malaysia

3 Department of Chemistry, State Key Laboratory of Marine Pollution, City University of Hong Kong, Tat Chee Avenue, Kowloon Tong, Hong Kong

4 Department of Aquatic Resources Management, Bogor Agricultural University, Bogor, Indonesia

5 Horseshoe Crab Research Unit, Department of Bioscience and Biotechnology, Fakir Mohan University, Balasore, Odisha 756020, India

6 Japan Society for the Conservation of Horseshoe Crabs, Kasaoka City, Okayama, Japan

7 Research Institute of Environment for Sustainability, Faculty of Engineering, Kyushu University, Fukuoka, Japan

8 Center for Coastal and Marine Resources Studies, Bogor Agricultural University (IPB), Kampus IPB Baranangsiang, Jalan Raya Pajajaran, Bogor 16143, Indonesia 